\title{
Motivation to Quit Smoking after Acute Coronary Syndrome
}

\section{Motivação para Parar de Fumar após Síndroma Coronária Aguda}

\author{
Vânia ROCHA $₫ 1$, Marina GUERRA ${ }^{1}$, Marina LEMOS ${ }^{1}$, Júlia MACIEL ${ }^{2}$, Geoffrey WILLIAMS 3 \\ Acta Med Port 2017 Jan;30(1):34-40 - http://dx.doi.org/10.20344/amp.7926
}

\section{ABSTRACT}

Introduction: Self-Determination Theory explores the process through which a person acquires motivation to initiate new behaviours related to health and to maintain them over time. This study aimed to determine the overall fit of Self-Determination Theory Model for Health Behavior to the data obtained from a sample of smokers hospitalized with acute coronary syndrome, and to identify the predictors of smoking status six months after clinical discharge.

Material and Methods: The sample included 110 participants, regular smokers, hospitalized due to acute coronary syndrome. Questionnaires were administered to assess autonomous self-regulation, perceived competence, family support, depressive symptoms and meaning in life. Participants were asked if they were currently smokers six months after clinical discharge.

Results: The results showed that the process variables specified by Self-Determination Theory fit the data well. Perceived competence predicted abstinence from smoking six months after clinical discharge.

Discussion: Our findings have similar characteristics to other international samples in which Self-Determination Theory models have been tested. It is important to facilitate perceived competence, as the patients who continue to smoke have shorter length of life.

Conclusion: This study highlights the importance of considering clinical interventions based on Self-Determination Theory to facilitate smoking cessation.

Keywords: Acute Coronary Syndrome/psychology; Motivation; Smoking; Smoking Cessation

\section{RESUMO}

Introdução: A Teoria da Auto-Determinação explora os processos através dos quais as pessoas adquirem motivação para adoptar comportamentos promotores de saúde e para mantê-los ao longo do tempo. Pretendemos testar o Modelo de Saúde da Teoria de Auto-Determinação numa amostra de fumadores hospitalizados devido a síndroma coronária aguda, e identificar preditores da abstinência tabágica seis meses após alta hospitalar.

Material e Métodos: Incluímos no estudo 110 participantes, fumadores, hospitalizados devido a síndroma coronária aguda. Aplicamos questionários para avaliar a regulação autónoma, competência percebida, suporte familiar, depressão e sentido de vida no momento do internamento. Questionamos os participantes se continuavam a fumar seis meses depois.

Resultados: Os resultados demonstraram que os processos definidos pela Teoria da Auto-Determinação se ajustam bem aos dados da amostra. A competência percebida prediz positivamente a abstinência tabágica seis meses após alta hospitalar.

Discussão: Os resultados são similares aos encontrados noutras amostras internacionais nas quais o modelo da Teoria da AutoDeterminação foi testado. É importante promover a competência percebida para parar de fumar, pois é reconhecido que pacientes com doença cardíaca que continuam a fumar apresentam menor longevidade e qualidade de vida.

Conclusão: Este estudo salienta a importância de se investir em intervenções clínicas baseadas na Teoria da Auto-Determinação para promover a cessação tabágica.

Palavras-chave: Abandono do Hábito de Fumar; Motivação; Síndroma Coronária Aguda/psicologia; Tabagismo

\section{INTRODUCTION}

Tobacco dependence kills approximately six million people worldwide each year and affects $20 \%$ of the Portuguese population. ${ }^{1,2}$ Despite the known benefits of not smoking, relapses are common even after an acute coronary syndrome. ${ }^{3}$ Thus, it is crucial to understand the behaviour of smokers who have suffered an acute coronary syndrome concerning their motivation to quit smoking. Interventions that enhance motivation for cessation, and result in abstinence are expected to improve quality and length of life. Self-Determination Theory (SDT), a general theory of human motivation, posits processes through which humans internalize motivation to initiate new behaviours related to health and to maintain them over time..$^{4,5}$
According to tenets of SDT, there are three types of motivation or behavioural regulations: autonomous selfregulation (ASR), controlled regulation, and amotivation. ${ }^{6}$ ASR refers to the regulation of behaviour taking into account personal interests and values inherent to the subject, involving a sense of volition and choice. ${ }^{7,8}$ People who smoke are autonomously self-regulated if they attempt to stop smoking because it is important to them personally or congruent with deeply held values. ${ }^{9}$ Controlled regulation implies that individuals feel pressured or coerced by intrapsychic or interpersonal factors. People who smoke have controlled regulations if they attempt to quit smoking due to a demand, threat or reward of an external agent

1. Faculdade de Psicologia e de Ciências da Educação. Universidade do Porto. Porto. Portugal.

2. Faculdade de Medicina. Universidade do Porto. Porto. Portugal.

3. Medical Center. University of Rochester. Rochester. United States of America.

$\triangle$ Autor correspondente: Vânia Rocha. vmasrocha@gmail.com.

Recebido: 11 de junho de 2016 - Aceite: 26 de agosto de 2016 | Copyright @ Ordem dos Médicos 2017 
(e.g. doctor or family member) or to avoid feelings of guilt and shame. ${ }^{8}$ For example, patients who stopped smoking "necessarily" because of their cardiac pathology, but do not inherently recognize other benefits of abstaining. ${ }^{10}$ Controlled regulation is associated with type A coronary prone behavioural pattern. ${ }^{4}$ Amotivation is represented by a lack of intention to act.

Another psychological need posited by SDT to explain initiation and maintenance of health-behaviours is perceived competence (PC). ${ }^{8} \mathrm{PC}$, along with autonomy and relatedness, are basic needs essential to person's wellbeing. PC refers to people's feelings of being effective in their interactions with the environment and social contexts in achieving desired outcomes. In the context of this study, PC refers to the extent which subjects feel capable of stop smoking permanently. According to SDT, providing autonomy and competence support enhances the persons' perceptions of autonomy and competence for changing and maintaining the specific behaviour. Autonomy support can be defined as eliciting and acknowledging the patients' perspective, supporting their initiatives and minimizing control. ${ }^{8}$ It can be provided by practitioners, but also by family members and significant others.

Support and satisfaction of the basic needs are critical to the process of internalization and integration of values and ASR, by which humans are energized, to sustain behaviours conductive to health, well-being and personal growth. ${ }^{11}$ The satisfaction of basic needs is associated with better health-related outcomes, such as initial and long-term maintenance of smoking abstinence and less symptoms of depression. ${ }^{5,12,13}$ But if the needs are not satisfied, various non-adaptive reactions can emerge (e.g. depression and anxiety). Depressive symptoms can be an obstacle to achieve smoking abstinence, as many people smoke as a coping mechanism to deal with negative feelings. ${ }^{14}$

Meaning in life is a positive psychological construct that has recently started to be studied in samples of patients with heart disease, as well as in samples of smokers. This concept was defined as a sense of clear aims in life, a sense of achieving life goals, and a feeling that one's experiences and daily activities are worthwhile and meaningful. ${ }^{15}$ People who do not experience meaning in life tend to feel an inner emptiness, a deep discontent, and boredom that increase the probability of the occurrence of mood and addictive disorders, such as smoking dependence. ${ }^{16}$ Meaning in life is an outcome of basic need satisfaction: only pursuits that provide basic needs satisfaction will be experienced as meaningful. ${ }^{17}$ Autonomy, relatedness, and competence facilitate people's engagement with new challenges with openness and interest and allow richer opportunities for them to create meaning in life. Conversely, need deprivation is expected to lead to amotivation, meaninglessness and ill-being.

We only found one study that tested SDT in a sample of smokers with heart disease. ${ }^{18}$ There was no study that tested the SDT model in a sample of Portuguese smokers who also suffered an acute coronary syndrome. We believe that Portuguese population probably has different characteristics than other samples in which the SDT model has been tested. In Portugal, smoking was well accepted until 2008, when the Portuguese government enacted a public policy prohibiting smoking in public places. In our opinion, the behavioural dimension of smoking is more rooted among Portuguese people than among other countries where this type of law has existed for decades. ${ }^{19}$

The present study aimed to determine the overall fit of the SDT to the data obtained from the sample and identify if the variables included in the model predict smoking status six months after clinical discharge. This included testing the SDT principles studied in international studies in a Portuguese sample of patients who suffered an acute coronary syndrome and who were also smokers. Previous research based on SDT has revealed causal associations among creation of an intervention for tobacco dependence based on SDT, autonomy support, change in ASR and PC, and initial and maintained cessation, thus supporting the SDT model of health behaviour. ${ }^{5,12}$ Another innovation of this study was the inclusion of meaning in life in the SDT model for health behaviour. We considered depressive symptoms and meaning in life as mental health-outcomes of ASR and $P C$ as, according to SDT, the satisfaction of the basic psychological needs is associated with less mental health symptoms and higher meaning in life. ${ }^{13,17}$ Thus, this study hypothesized that family support would positively affect the persons' ASR and PC, which in turn would positively predict better health-related outcomes (less depressive symptoms and a higher meaning in life) and negatively predict smoking six months after clinical discharge.

\section{MATERIAL AND METHODS \\ Participants}

One-hundred and ten patients were recruited from the department of cardiology of Centro Hospitalar de São João (CHSJ) and Centro Hospitalar de Vila Nova de Gaia (CHVNG) in Portugal through a consecutive sampling technique. Participants were included in this study if they had Portuguese nationality, were 18 years of age or older, were regular smokers (smoke a minimum of five cigarettes per day), and were hospitalized with the diagnosis of acute coronary syndrome (acute myocardial infarction or unstable angina). Participants were excluded if they had cognitive impairment or psychiatric disorders (dementia or psychosis). Following this protocol, all eligible patients admitted in both departments from November 2013 to July 2014 were approached to participate in the study. Of the 113 patients who met eligibility criteria, three declined due to lack of willingness to enrol. Of the 110 participants, $89 \%$ were men and $96 \%$ were diagnosed with myocardial infarction. The mean age was $55.03(S D=10.12)$ and on average participants smoked 20 cigarettes a day $(\mathrm{M}=$ $19.90, \mathrm{SD}=9.55$.

\section{Instruments}

The Treatment Self-Regulation Questionnaire (TSRQ) 
assessed ASR for smoking cessation. ${ }^{20}$ Responses were made on a seven point Likert-type scale that ranged from one ('not true') to seven ('totally true'). TSRQ was validated for the Portuguese population and the Cronbach's alpha reported for this measure was 0.83 (Guerra M, personal communication).

The Perceived Competence Scale (PCS) assessed PC to stop smoking successfully. ${ }^{21}$ Responses were made on a seven point Likert-type scale that ranged from one ('not true') to seven ('totally true'). PCS was validated for the Portuguese population and the Cronbach's alpha reported for this measure was 0.83 (Guerra M, personal communication).

The Instrumental-Expressive Social-Support Scale (IESSS) assessed family support. ${ }^{22}$ Responses were made on a five point Likert-type scale that ranged from one ('always') to five ('never'). IESSS was validated for the Portuguese population and the Cronbach's alpha reported for this measure was $0.83 .^{23}$

The Hospital Anxiety and Depression Scale (HADS) assessed depressive symptoms. ${ }^{24}$ Responses were made on a four point Likert-type scale that ranged from zero to three. HADS was validated for the Portuguese population and the Cronbach's alpha reported for this measure was 0.81 .25

The Escala de auto-actualização - sentido de vida (EACSV) assessed the dimension of meaning in life. Responses were made on a five point Likert-type scale that ranged from one ('totally agree') to five ('totally disagree'). A confirmatory factor analysis was performed and the Cronbach's alpha reported for this measure was $0.76 .^{26}$

\section{Procedure}

This study was approved by the ethics committee of CHSJ and CHVNG and it was followed the ethical protocol of both hospitals. The instruments were consecutively administered to each patient who met the inclusion criteria admitted at the Cardiology Department of CHSJ and CHVNG in the order previously described, during the period established for the data collection. It assured confidentiality and informed consent was obtained according to the Helsinki Declaration. All participants were asked if they were currently smokers or ex-smokers six months after clinical discharge, with a yes/no question. Forty-four participants were contacted personally on the day of their cardiologist appointment at the hospitals where the data collection took place. The ones who were being followed at other hospitals
(66 participants) were contacted by post mail. Of the 110 participants that enrolled in the study, one participant died and 33 did not respond to the post mail.

\section{Statistical analysis}

Structural equation modeling (SEM) was used to determine the extent to which the hypothesized SDT model was supported by the data. The Pearson's correlation coefficient provides the basis for establishing and testing the proposed models. ${ }^{27}$ Thus, Pearson's correlation analysis between family support, ASR, PC, depressive symptoms and meaning in life were performed to examine their associations and to determine whether to add them to the model. All variables in the analysis were significantly correlated, except for the correlations between ASR and meaning in life $(r=0.13, p=0.18)$, and family support and depressive symptoms $(r=-0.17, p=0.08)$ (Table 1). Thus, all variables were kept in the model.

Due to the number of variables and the high number of indicators per latent construct in relation to the sample size, all variables were treated as observed variables rather than latent variables. The regression coefficients significance was assessed after parameter estimation through the maximum likelihood method implemented in the AMOS software ( $v$. 21). No one of the variables showed skewness (Sk) and kurtosis $(\mathrm{Ku})$ values that indicated severe violations of the normal distribution (Sk < 3 and $\mathrm{Ku}<10$, Marôco, 2014). The Mahalanobis square distance values indicated the existence of outliers. The analysis was repeated without the outliers, showing that there was a significant difference between the results obtained and the ones from the initial analysis. According to the literature, if there is a significant difference between the model estimates with and without outliers, it should be considered the inclusion of the outliers in the analysis. ${ }^{28}$ Thus, the outliers were kept in the analysis, as a part of the phenomena under study. No one of the variables presented VIF indicators of multicollinearity (VIF $<5) .{ }^{28}$ The significance of the direct and indirect effects was evaluated through Bootstrap resampling. ${ }^{28}$ Effects at $p \leq 0.05$ were considered as statistically significant. The path coefficients were standardized estimates.

We did not include smoking status in the model, because path analysis models do not accept dichotomous variables as endogenous variables. We performed a direct logistic regression (enter method) to identify the impact of the variables included in the model on the likelihood that participants would report that they smoked six months

Table 1 - Correlations among observed variables

\begin{tabular}{|c|c|c|c|c|c|}
\hline & 1 & 2 & 3 & 4 & 5 \\
\hline 1. Family support & - & $0.25^{*}$ & $0.25^{\star *}$ & -0.17 & $0.29^{* *}$ \\
\hline 2. Autonomous self-regulation & & - & $0.48^{* *}$ & $-0.24^{*}$ & 0.13 \\
\hline 3. Perceived competence & & & - & $-0.23^{*}$ & $0.22^{*}$ \\
\hline 4. Depressive symptoms & & & & - & $-0.41^{\text {** }}$ \\
\hline 5. Meaning in life & & & & & - \\
\hline
\end{tabular}


after clinical discharge. We only include in the model the variables that were significant at a bivariate level. Thus, we performed an independent-samples t-test to investigate the relationship of smoking status six months after clinical discharge with family support, ASR, PC, depressive symptoms, and meaning of life. Only PC and meaning in life were statistically significant (Table 2). Thus, the logistic regression model contained two independent variables (PC and meaning in life).

\section{RESULTS}

Descriptive statistics of the motivation and psychosocial variables in the study were calculated. The mean score for family support was 13.61 (SD = 1.94). The mean score for ASR and PC was $6.15(S D=1.19)$ and $5.70(S D=1.38)$ respectively, which showed that participants had high levels of ASR and perceived themselves as competent to quit smoking. The mean score for depressive symptoms was 5.30 (SD = 3.60), which stood below the established cut-off point $(7 / 21)$ for depression. ${ }^{25}$ The mean score for meaning in life $(M=26.88, S D=3.27)$ was lower than the observed in other samples. ${ }^{26}$ Of the 76 participants who answered our question concerning their smoking status six months after clinical discharge, 44 were ex-smokers and 32 were smokers.

One of our main goals was to test the overall fit of SDT model to the data obtained in our sample. A path analysis model was established between the variables family support, ASR, PC, depressive symptoms and meaning in life. Fig. 1 shows the model with the standardized estimates of the regression coefficients and the $\mathrm{R}^{2}$ of $A S R, P C$, depressive symptoms and meaning in life.

The adjusted model explained $6 \%$ and $23 \%$ of the variability of ASR and $\mathrm{PC}$ respectively. It also explained $5 \%$ of the variability of depressive symptoms and meaning in life. All evaluated trajectories were positive and statistically significant, except for the path PC depressive symptoms that was negative and statistically significant. Family support related positively to ASR $(\beta=0.24, p<0.005)$, ASR related positively to $P C(\beta=0.48, p<0.005), P C$ related negatively to depressive symptoms $(\beta=-0.23, p<0.005)$ and positively to meaning in life $(\beta=0.22, p<0.005)$. Thus, all hypothesized relations were significant and in the direction predicted. As for the indirect effects, family support showed an indirect effect of 0.12 on PC (mediated by ASR), of -0.03 on depressive symptoms and of 0.03 on meaning in life (both mediated by ASR and PC). ASR showed an indirect effect of -0.11 on depressive symptoms and of 0.11 on meaning in life (both mediated by PC). According to the Bootstrap resampling method, all effects were significant $(p<0.05)$, except for the family support indirect effects concerning $\mathrm{PC}(p=0.13)$, depressive symptoms $(p=0.10)$

Table 2 - Independent-samples T-test between observed variables and smoking status six months after clinical discharge

\begin{tabular}{|c|c|c|c|c|c|c|c|}
\hline \multirow[b]{2}{*}{ Variable } & \multicolumn{2}{|c|}{$\begin{array}{c}\text { Ex-smokers } \\
(n=44)\end{array}$} & \multicolumn{2}{|c|}{$\begin{array}{l}\text { Smokers } \\
(n=32)\end{array}$} & \multirow[b]{2}{*}{$t$} & \multicolumn{2}{|c|}{$95 \% \mathrm{Cl}$} \\
\hline & M & SD & $M$ & SD & & LL & UL \\
\hline Family support & 13.93 & 1.48 & 13.444 & 2.37 & 1.04 & -0.46 & 1.45 \\
\hline Autonomous self-regulation & 6.392 & 1.04 & 6.02 & 1.18 & 1.48 & -0.13 & 0.89 \\
\hline Perceived competence & 6.20 & 1.11 & 5.39 & 1.20 & $3.05^{*}$ & 0.28 & 1.35 \\
\hline Depressive symptoms & 5.02 & 3.04 & 5.50 & 4.14 & -0.55 & -2.21 & 1.25 \\
\hline Meaning in life & 27.66 & 2.88 & 25.88 & 3.57 & $2.41^{*}$ & 0.31 & 3.26 \\
\hline
\end{tabular}

n: 76; Cl: Confidence interval; LL: Lower limit; UL: Upper limit; * $p<0.05$

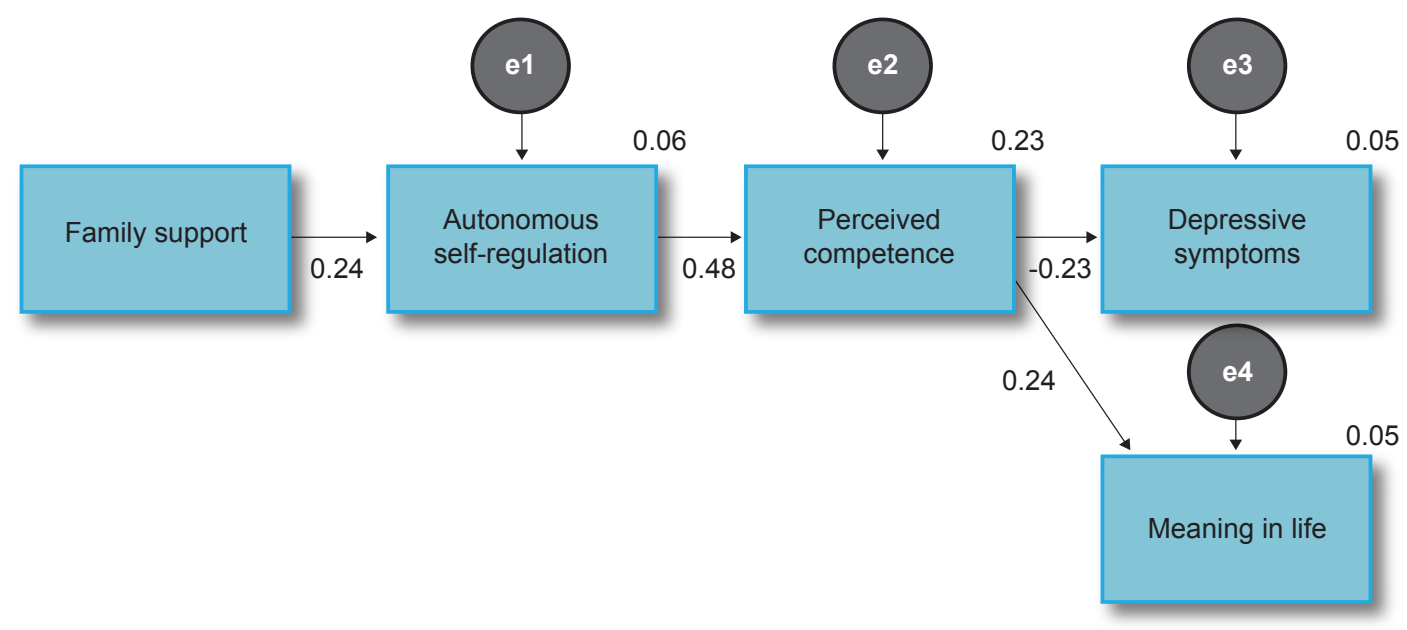

Figure 1 - Path analysis model between family support, autonomous self-regulation, perceived competence, depressive symptoms and meaning in life 
Table 3 - Logistic regression predicting smoking status six months after clinical discharge

\begin{tabular}{lccccc}
\hline & & & & \multicolumn{2}{c}{$95 \% \mathrm{Cl}$ for OR } \\
\cline { 3 - 6 } Variable & B & S.E. & OR & LL & 0.38 \\
Perceived competence & $-0.55^{*}$ & 0.22 & 0.58 & 0.89 & 1.01 \\
Meaning in life & -0.17 & 0.09 & 0.84 & 0.70 & \\
Constant & 7.50 & 2.77 & & & \\
\hline
\end{tabular}

n: 76; Cl: Confidence interval; OR: Odds ratio; LL: Lower limit; UL: Upper limit; Model $\chi^{2}(2): 12.79 ;{ }^{*} p<0.05$

and meaning in life $(p=0.10)$.

Another goal of our study was to identify predictors of the participants' smoking status six months after clinical discharge. A logistic regression was performed and the full model containing $\mathrm{PC}$ and meaning in life as predictors was statistically significant, $\chi^{2}(2, \mathrm{n}=76)=12.79, p<0.01$, indicating that the model was able to distinguish between participants who were smokers and non-smokers. The model as a whole explained between $15.5 \%$ (Cox and Snell R square) and $20.8 \%$ (Nagelkerke $\mathrm{R}$ squared) of the variance in smoking status, and correctly classified $65.8 \%$ of cases. Only PC made a unique statistically significant contribution to the model, recording an odds ratio of 0.58 , a value less than one (Table 3 ). This indicated that participants who experienced $\mathrm{PC}$ to quit smoking were 0.58 times less likely to report that they smoked than those who did not present $\mathrm{PC}$ to quit smoking, controlling for all other factors in the model.

\section{DISCUSSION}

The present study aimed to test the overall fit of SDT to the data collected from a sample of patients hospitalized due to an acute coronary syndrome who smoke, and to identify predictors of smoking status six months after clinical discharge. The results indicate that Portuguese patients who have suffered an acute coronary syndrome are more likely to have stopped smoking six months later if they feel more competent for quitting. Also, the data fit the SDT model for health behaviour well, and as found in other health related studies. ${ }^{6}$ These results are the first to show that meaning in life was significantly associated with the SDT model as predicted. Our findings have similar characteristics to other international samples in which SDT models have been tested. Thus, this study extends the cross-cultural generalizability of SDT.

Specifically, the results of the study supported several important principles of the SDT model for health behaviour. Family support was positively related to ASR to quit smoking. Support from others is crucial in motivating autonomous change of different health related behaviours, as it supports that humans inherently internalize ASR when psychological needs are supported. ${ }^{8}$ Autonomy supportive environments allow patients to have more positive perceptions of autonomy and competence, facilitating their engagement in autonomously regulated behaviours and in treating their illness or physical / psychological condition. A study with 865 smokers found that important others' autonomy support at one month predicted six-month levels of ASR for quitting smoking. ${ }^{29}$ In a recent study, patients who received extratreatment support from others (e.g. family, co-workers, or friends), when they tried to quit smoking, had a $50 \%$ increase in their five-month abstinence rates. ${ }^{30}$

The results again confirmed that ASR was positively related to PC to quit smoking. This finding also supports SDT model of health behaviour which states that gaining a sense of competence is facilitated by higher levels of perceived autonomy. ${ }^{11}$ Some studies demonstrated that smokers who reported greater ASR to quit smoking, felt more competent to change. ${ }^{8}$ People experience a high degree of willingness to act when they are autonomously regulated, which makes them more apt to learn and apply new strategies and competencies. ${ }^{31}$ This finding is important to health-care practitioners' interventions, as many times there is a tendency for using a directive style when teaching strategies to patients to quit smoking, rather than exploring their willingness to stop smoking first, before teaching them how to.

PC was related to better mental and physical health outcomes. It showed a negative direct effect on depressive symptoms and a positive direct effect on meaning in life. This is a novel finding that is likely to be important in the ongoing health of patients with cardiovascular disease, as those with higher levels of depressive symptoms have shorter length of life and a worse quality for the years they do live. ${ }^{32}$ The basic needs satisfaction is associated with better mental health (less depressive symptoms). ${ }^{11}$ Several studies have shown that patients who suffered a heart attack have difficulties in self-regulating and modulating disturbing emotions, which can be a reason for them to initiate and maintain addictive behaviours. ${ }^{33}$ Although meaning in life is not included as a component of SDT, the results showed that it is significantly linked to PC. The satisfaction of the basic psychological needs facilitate meaning in life..$^{17}$ If people perceive themselves as competent in their interactions with the environment and social contexts, it is more likely for them to initiate and maintain new behaviours over time, which can facilitate a sense of achieving life goals (meaning in life). Some studies found that meaning in life was a significant negative predictor of cigarette consumption, and that it was associated with enhanced psychological adjustment among individuals with severe medical condition. ${ }^{34,35}$ This study demonstrates that meaning in life is associated with SDT constructs for changing an important health behaviour. Although this is a novel finding, further studies are needed to demonstrate that SDT interventions that promote autonomy and competence lead to greater meaning in life. 
PC predicted abstinence from smoking six months after clinical discharge. Participants, who felt greater PC, were less likely to continue smoking six months after an acute coronary syndrome. SDT based interventions that have focused on enhancing PC and ASR have shown that $P C$ is a potent mediator of prolonged abstinence from tobacco. ${ }^{12}$ Evidence showed that both change in ASR and PC facilitated long-term smoking abstinence. ${ }^{5,18,36}$

This study also enhances the importance of administering instruments to assess the patients' family support, ASR, PC, depressive symptoms and meaning in life during hospitalization and after clinical discharge, in order to improve the effectiveness of tobacco dependence interventions in the future.

Some limitations of this study deserve mention. Our sample was a convenience sample, as it was only collected in the district of Porto, Portugal. A control group would be useful to determine if the findings reflected characteristics of people who suffered an acute coronary syndrome or if they would be identical in a healthy sample, or samples of people with other diseases. An extended follow-up would be critical to better inform how best to intervene to promote prolonged abstinence from cigarette smoking and greater meaning and quality of life for smokers with cardiovascular disease.

\section{REFERENCES}

1. World Health Organization. WHO report on the global tobacco epidemic: Enforcing bans on tobacco advertising, promotion and sponsorship. Luxembourg: WHO Press; 2013.

2. Direção Geral da Saúde. Programa Nacional para a Prevenção e Controlo do Tabagismo. Portugal - prevenção e controlo do tabagismo em números 2015. Lisboa: DGS; 2016.

3. Gavina C, Pinho T, Maciel J. Enfarte agudo do miocárdio. Vila do Conde: QuidNovi; 2011.

4. Deci EL, Ryan RM. The 'what' and 'why' of goal pursuits: Human needs and the self-determination of behaviour. Psychol Inquiry. 2000;11:22768.

5. Williams GC, Niemiec CP, Patrick H, Ryan RM, Deci EL. The importance of supporting autonomy and perceived competence in facilitating longterm tobacco abstinence. Ann Behav Med. 2009;37:315-24.

6. $\mathrm{Ng}$ J, Ntoumanis $\mathrm{N}$, Thøgersen-Ntoumani C, Deci E, Ryan R, Duda J, et al. Self-determination theory applied to health contexts: A meta-analysis. Perspect Psychol Sci. 2012;7:325-40.

7. Ryan RM, Deci EL. An overview of self-determination theory. In: Deci EL, Ryan, RM, editors. Handbook of self-determination research, Rochester: University of Rochester Press; 2002, p. 3-33.

8. Williams GC, Minicucci DS, Kouides RW, Levesque CS, Chirkov VI, Ryan RM, et al. Self-determination, smoking, diet and health. Health Educ Res. 2002;17:512-21.

9. Williams GC, Patrick H, Niemiec CP, Ryan RM, Deci EL, Lavigne HM. The smoker's health project: A self-determination theory intervention to facilitate maintenance of tobacco abstinence. Contemp Clin Trials. 2011;32:535-43.

10. Guerra MP. A abstenção tabágica: Reflexões sobre a recaída. Análise Psicológica. 2004;3:507-18.

11. Ryan R, Patrick H, Deci E, Williams G. Facilitating health behaviour change and its maintenance: Interventions based on Self-determination theory. Eur Health Psychologist. 2008;10:2-5.

12. Williams GC, McGregor H, Sharp D, Kouides RW, Lévesque CS, Ryan

\section{CONCLUSION}

It is important to include patients' perceptions of support from important others in tobacco dependence interventions and to invest in interventions that facilitate ASR and PC in individuals who are hospitalized due to acute coronary syndrome. These interventions are more likely to help them quit smoking successfully and to achieve better mental health outcomes (less depressive symptoms and higher meaning in life), which can potentially facilitate coping with the disease.

\section{PROTECTION OF HUMANS AND ANIMALS}

The authors declare that the procedures were followed according to the regulations established by the Clinical Research and Ethics Committee and to the Helsinki Declaration of the World Medical Association.

\section{DATA CONFIDENTIALITY}

The authors declare having followed the protocols in use at their working center regarding patients' data publication.

\section{CONFLICTS OF INTEREST}

The authors declare that there are no conflicts of interest.

\section{FUNDING SOURCES}

This research received no specific grant from any funding agency in the public, commercial, or not-for-profit sectors.

$\mathrm{RM}$, et al. A self-determination multiple risk intervention trial to improve smokers health. J Gen Intern Med. 2006;21:1288-94.

13. Williams GC, Lynch M, Glasgow RE. Computer-assisted intervention improves patient-centered diabetes care by increasing autonomy support. Health Psychol. 2007;26:728-34.

14. Royal College of Physicians. Harm reduction in nicotine addiction: Helping people who can't quit. A report by the tobacco advisory group of the Royal College of Physicians. London: RCP; 2007.

15. Marsh A, Smith L, Piek J, Saunders B. The Purpose in life scale: psychometric properties for social drinkers and drinkers in alcohol treatment. Educ Psychol Meas. 2003;63:859-71.

16. Frankl V. On the theory and therapy of mental disorders. An introduction to logotherapy and existential analysis. New York: Brunner-Routledge; 2004.

17. Weinstein N, Ryan R, Deci E. Motivation, meaning, and wellness. A self-determination perspective on the creation and internalization of personal meanings and life goals. In: Wong $P$, editor. The Human quest for meaning, New York: Routledge; 2012, p. 81-106.

18. Williams GC, Gagné M, Mushlin A, Deci E. Motivation for behavior change in patients with chest pain. Health Educ. 2005;105:304-21.

19. Rocha V, Guerra MP, Lemos MS, Glover ED. Validation of the GloverNilsson smoking behavioural questionnaire for the Portuguese population: A psychometric process. Am J Health Behav. 2014;38:801-6.

20. Lévesque CS, Williams GC, Elliot D, Pickering MA, Bodenhamer B, Finley PJ. Validating the theoretical structure of the Treatment Self-Regulation Questionnaire (TSRQ) across three different health behaviours. Health Educ Res. 2007;22:691-702.

21. Ryan RM, Deci EL. Self-determination theory and the facilitation of intrinsic motivation, social development and well-being. Am Psychol. 2000; 55:68-78.

22. Lin N, Dean A, Ensel W. Social support, life events and depression. New York: Academic Press; 1986.

23. Guerra MP. Uma escala de avaliação do suporte social: Aplicação numa 
população seropositiva ao vírus HIV. Avaliação Psicológica: Formas e Contextos. 1995;3:25-34.

24. Zigmond AP, Snaith RP. The hospital anxiety and depression scale. Acta Psychiatr Scand. 1983;67:361-70.

25. Ribeiro JP, Silva I, Ferreira T, Martins A, Meneses R, Baltar M. Validation study of a Portuguese version of the hospital anxiety and depression scale. Psychol, Health \& Med. 2007;12:225-37.

26. Guerra M, Lencastre L, Silva E, Teixeira P. Meaning of life in medical settings. Cogent Psychology. 2016. (In press)

27. Schumacker R, Lomax R. A beginner's guide to structural equation modeling. New York: Routledge; 2010.

28. Marôco J. Análise de equações estruturais: fundamentos teóricos, software e aplicações. Pêro Pinheiro: ReportNumber; 2014.

29. Williams GC, Lynch M, McGregor H, Ryan R, Sharp D, Deci E. Validation of the "Important Other" Climate Questionnaire: Assessing autonomy support for health-related change. Fam Syst Health. 2006;24:179-94.

30. Fiore M, Bailey W, Cohen S, Dorfman S, Goldstein M, Gritz E, et al.
Treating tobacco use and dependence. Rockville: U.S. Department of Health and Human Services; 2000.

31. Markland D, Ryan RM, Tobin VJ, Rollnick S. Motivational interviewing and self-determination theory. J Soc Clin Psychol. 2005;24:811-31.

32. Burg MM, Barefoot J, Berkman L, Catellier DJ, Czajkowski S, Saab $\mathrm{P}$, et al. Low perceived social support and post-myocardial infarction prognosis in the enhancing recovery in coronary heart disease clinical trial: The effects of treatment. Psychosom Med. 2005;67:879-88.

33. Rocha V, Guerra MP, Maciel MJ. Dependência tabágica, assertividade e alexitimia em doentes cardíacos. Paidéia. 2010;20:155-64.

34. Thege BK, Bachner YG, Martos T, Kushnir T. Meaning in life: does it play a role in smoking? Subst Use Misuse. 2009;44:1566-77.

35. Sherman AC, Simonton S. Effects of personal meaning among patients in primary and specialized care: Associations with psychosocial and physical outcomes. Psychol Health. 2012;27:475-90.

36. Williams GC, Gagné M, Ryan RM, Deci EL. Facilitating autonomous motivation for smoking cessation. Health Psychol. 2002;21:40-50. 